\title{
Antibiogram of Bacteria Isolated From Pre-School Children with Asymptomatic Bacteriuria
}

\author{
Jacinta C. Elo-Ilo ${ }^{1, ~ *, ~ E l o c h u k w u ~ C a j e t a n ~ I l o ², ~ S y l v i a ~ O . ~ A n y a d o h-N w a d i k e ~}{ }^{3}$ \\ ${ }^{1}$ Department of Paediatrics, Nnamdi Azikiwe University Awka / Nnamdi Azikiwe UniversityTeaching Hospital Nnewi, Anambra State, Nigeria \\ ${ }^{2}$ Department of Pharmacology and Therapeutics, Nnamdi Azikiwe University Awka, Anambra State, Nigeria \\ ${ }^{3}$ Department of Biotechnology, Federal University of Technology, Owerri, Imo State, Nigeria
}

Email addresses:

jc.elo-ilo@unizik.edu.ng (J. C. Elo-Ilo), ec.ilo@unizik.edu.ng (E. C. Ilo), sylanyad@yahoo.com (S. O. Anyadoh-Nwadike)

\section{To cite this article:}

Jacinta C. Elo-Ilo, Elochukwu Cajetan Ilo, Sylvia O. Anyadoh-Nwadike. Antibiogram of Bacteria Isolated From Pre-School Children with Asymptomatic Bacteriuria. Science Journal of Public Health.Special Issue: Who Is Afraid of the Microbes. Vol. 3, No. 5-1, 2015, pp. 34-39. doi: $10.11648 /$ j.sjph.s.2015030501.17

\begin{abstract}
Under five mortality which implies the death of a child before his or her fifth birthday is a major problem in developing countries like Nigeria. Aside other factors; microbial infection is grossly implicated in under five mortality. More problems however are caused by antimicrobial resistant microorganisms. Antimicrobial resistance by bacteria has become a global problem leading to much treatment failure. This study was therefore carried out to ascertain the antimicrobial profile of clinical isolates from pre-nursery school children between the ages of 3 and 5 years with a view to proposing the antibiotic of choice against the common isolates. Known isolates from pre-school children in Nnewi were used for the study. These isolates were subjected to standard microbiological and biochemical protocols to confirm their identities. The disc diffusion method was used to ascertain the susceptibility of the test organisms to commonly used broad spectrum antibiotics. Multidiscs containing ten broad spectrum antibiotics were used. The data obtained from this study were analyzed using the statistical package for social science (SPSS) version 9.5. The mean, range and standard deviation of the variables were determined where applicable. Frequency distribution, percentages and cross tabulation to examine relation between variables was done. The difference between frequencies was tested using Yate's corrected chi square $\left(\chi^{2}\right)$ test or Fisher's exact test. Statistical significance was set at $\mathrm{p}<0.05$. The overall invitro sensitivity of the isolates was $100 \%$ to ciprofloxacin, $90.6 \%$ to clindamycin, $68.8 \%$ to gentamicin and $59.4 \%$ to cefuroxime. Fifty percent of the isolate were sensitive to cephalexim. The isolate were $34.4 \%$ sensitive to nitrofuraintoin and nalidixic acid, 25\% sensitive to cotrimoxaole and 9.4\% sensitive to erythromycin. All isolates were resistant to ampicillin.
\end{abstract}

Keywords: Antibiogram, Bacteria, Bacteriuria, Resistance

\section{Introduction}

Microorganisms are ubiquitous in nature. They are seen living in/on a wide range of natural habitats. It is therefore not surprising to find them growing abundantly on surfaces of the human body including the skin and Gastro Intestinal Tract (GIT). Only a small proportion of microorganisms are associated with man either as commensals or pathogens [1, 2]The commensals are found living on the skin, mucous membranes of the upper respiratory, intestinal tracts and female genital canals obtaining nourishment from the secretions and/or food residues. These therefore constitute the normal flora of the healthy body being well established on the external and internal surfaces of the body without causing harm $[2,3]$. Under favourable conditions, when the body's defenses are compromised, normally harmless organisms may invade and cause diseases/infections. They are called opportunistic pathogens and pose great threats to man. They are therefore of serious public health concern. The true pathogens on the other hand have developed mechanisms of overcoming the normal defenses of the healthy body, they invade the tissue, proliferate and produce toxins which often cause damage to the tissues and result in the manifestation of disease [4].

Since the discovery of penicillin, more antibiotics have been produced with novel ingredients and mechanisms of action but the more the antibiotics, the more the pathogens found means of circumventing the effects of the antibiotics [3, 
5] leading to antibiotic resistance. Antibiotic resistance i.e. the character of bacteria to withstand the inhibitory or lethal effects of antibiotics indicates the versatility of bacteria in their struggle for existence [5]. Resistance is observed when microorganisms continue to grow at an attainable concentration in the presence of antimicrobial agents [6].

Clinically important drug resistant bacterial strains can circumvent effect of antibiotics by change/alteration of the structural target site for the drug, reduction in cellular permeability, conversion of the active substance to an inert product (via production of destructive enzymes) or via increased production of a biochemical intermediate [1, 3, 4].

Drug resistance is a large and growing problem in infections that account for most of Africa's disease burden, including urinary tract infections (UTIs) [7]. Development of resistance to these antimicrobial agents in UTI cases therefore affects treatment and management of the infection with these drugs. Adequate treatment and control of these conditions need a good knowledge of the bacteria species involved and their susceptibility to antimicrobial agents $[8,9]$. An antimicrobial agent is a chemotherapeutic agent used to treat the underlying cause of infectious diseases that is by inhibiting microbial growth and microbial survival [10].

Bacterial infections are usually treated with antibiotics. However, the antibiogram of different strains of microorganisms vary widely. Recently, high amoxicillin resistance of $E$. coli has been reported [9].

The development of resistance is inevitable following the introduction of a new antibiotic. Initial rates of resistance to new drugs are normally on the order of $1 \%$. However, modern uses of antibiotics have caused a huge increase in the number of resistant bacteria [3, 8]. Horizontal transfer of resistance among bacterial strains potentially poses serious danger in the community and hospital generally.

\subsection{Outcome of Asymptomatic Bacteriuria}

The natural history of ASB as regards outcome is that of short and long term morbidity and mortality. Without treatment, ASB resolves within weeks to months in approximately one third of girls with the infection. When examined months later whether treated or untreated, a high percentage $(24-80 \%)$ have the same persistent infection or have become re-infected with another stereotype or species. About $10 \%$ of these asymptomatic infections also become symptomatic [11]. Urinary infection symptomatic or asymptomatic carries the possible risk of renal scarring and up to $20 \%$ of cases of ASB have been localized to the upper urinary tract. Asymptomatic infections predispose to serious symptomatic infections $[12,13]$ hence the need for them to be checked and nipped in the bud.

Additionally, certain strains of $E$. coli that are frequently associated with urinary infections are more resistant to bactericidal activities than strains that seldom cause UTI [14]. In as much as microorganisms generally pose a threat to man, worse threats come from multidrug resistant pathogenic microorganisms $[8,9]$.

\subsection{Aim and Objective of the Study}

This study was aimed at determining the antibiogram / antimicrobial profile of clinical isolates from asymptomatic pre-nursery school children between the ages of 3 and 5 years with the view to creating awareness thereof as well as proposing the antibiotic of choice against the common isolates.

\section{Methodology}

\subsection{Source of Test Organisms}

Test bacteria were obtained from stock cultures of isolates from asymptomatic pre-nursery school children obtained by Elo-Ilo et al., [15]. These isolates were subjected to standard microbiological and biochemical tests as described by Cheesbrough [16] to further confirm their identities.

\subsection{Subculture}

The confirmed test isolates were then subcultured unto freshly prepared sterile nutrient agar medium using the methods of Cheesbrough [16] in order to obtain young cultures for the antibiotic sensitivity tests. The culture plates were incubated overnight at $37^{\circ} \mathrm{C}$.

\subsection{Antimicrobial Agents used}

Common broad spectrum antimicrobial agents in form of multidiscs were used. The multidisc comprised the following: Nitrofuraintoin $(100 \mu \mathrm{g})$, Gentamicin $(10 \mu \mathrm{g})$, Ciprofloxacin (5 $\mu \mathrm{g})$, Ampicillin $(25 \mu \mathrm{g})$, Nalidixic acid $(30 \mu \mathrm{g})$, Erytromycin $(10 \mu \mathrm{g})$, Clindamycin $(10 \mu \mathrm{g})$, Cotrimoxazole $(50 \mu \mathrm{g})$, Cefuroxime $(20 \mu \mathrm{g})$ and Cephalexin $(10 \mu \mathrm{g})$.

\subsection{Antibiotic Sensitivity Test}

Mueller Hinton agar and the Disc diffusion technique were used as prescribed by Clinical and Laboratory Standards Institute (CLSI) [17]. Pure colonies of the respective test bacteria were uniformly seeded unto already dried Mueller Hinton agar plates. The antibiotics discs (multidiscs) were then carefully placed centrally on the surface of the agar media. The plates were incubated at $37^{\circ} \mathrm{C}$ for 24 hours. After incubation, zones of inhibition or clearance of bacteria organisms around the respective antibiotics in the impregnated discs was noted and measured using a meter rule.

The results were compared against a previously prepared scale and reported as either sensitive or resistant. Zones of clearance of equal to or more than $3 \mathrm{~mm}$ were regarded as sensitive to the antibiotics while those of $2 \mathrm{~mm}$ and below were regarded as resistant [16].

The sensitivity of the Gram positive and Gram negative organisms to the different antibiotics were also compared.

\subsection{Statistical Analysis of Data}

The data obtained from this study were analyzed using the statistical package for social science (SPSS) version 9.5; The mean, range and standard deviation of the variables were determined where applicable. Frequency distribution, 
percentages and cross tabulation to examine relation between variables was done. The difference between frequencies was tested using Yate's corrected chi square $\left(\chi^{2}\right)$ test or Fisher's exact test. Statistical significance was set at $\mathrm{p}<0.05$.

\section{Results}

\subsection{Confirmation of the Identities of Test Organisms}

The isolates used were known isolates obtained from the study by Elo-Ilo et al., [15]. Their identities were however confirmed as follows: The identities of the Gram positive isolates were confirmed as Staphylococcus aureus (13 isolates), and Streptococcus faecalis (9 isolates) while the Gram negatives were confirmed to be Escherichia coli (5 isolates), Klebsiella spp (3 isolates) and Pseudomonas aeruginosa (2 isolates).

\subsection{Antibiotic Sensitivity Pattern (Antibiogram) of the Test Isolates}

All the organisms were sensitive to ciprofloxacin (100\%). They were $90.6 \%$ sensitive to clindamycin, $68.8 \%$ sensitive to gentamicin, $59.4 \%$ sensitive to cefuroxime and $50 \%$ sensitive to cephalexin. The sensitivity of nitrofurantoin, nalidixic acid, Erythromycin and cotrimoxazole were less than 35\%. All the test organisms were resistant to ampicillin. The antibiogram of the organisms are shown in Table 1 below.

The sensitivity of the Gram positive to the different antibiotics were higher when compared with and Gram negative organisms Table 2.

Table 1. Antibiogram of test organisms.

\begin{tabular}{|c|c|c|c|c|c|c|c|c|c|c|c|}
\hline \multirow{2}{*}{ Test Bacteria } & \multirow{2}{*}{ Freq } & \multicolumn{10}{|c|}{ Number (\%) susceptible/sensitive to } \\
\hline & & $\mathbf{N}$ & GN & CPX & AM & NA & $\mathbf{E}$ & CD & $\mathrm{CO}$ & CF & CX \\
\hline $\begin{array}{l}\text { Pseudomonas } \\
\text { aeruginosa }\end{array}$ & 2 & $0(0)$ & $2(100)$ & $2(100)$ & $0(0)$ & $2(100)$ & $0(0)$ & $2(100)$ & $0(0)$ & $0(0)$ & $1(50)$ \\
\hline $\begin{array}{l}\text { Staphylococcus } \\
\text { aureus }\end{array}$ & 13 & $4(30.8)$ & $7(53.8)$ & $13(100)$ & $0(0)$ & $4(30.8)$ & $2(15.4)$ & $13(100)$ & $1(7.7)$ & $7(53.8)$ & $8(88.9)$ \\
\hline $\begin{array}{l}\text { Streptococcus } \\
\text { faecalis }\end{array}$ & 9 & $5(55.6)$ & $6(66.7)$ & $9(100)$ & $0(0)$ & $1(11.1)$ & $1(11.1)$ & $8(88.9)$ & $3(33.3)$ & $7(77.8)$ & $3(33.3)$ \\
\hline $\begin{array}{l}\text { Klebsiella } \\
\text { species }\end{array}$ & 3 & $1(33.3)$ & $2(66.7)$ & $3(100)$ & $0(0)$ & $1(33.3)$ & $0(0)$ & $2(66.7)$ & $0(0)$ & $1(33.3)$ & $2(66.7)$ \\
\hline Escherichia coli & 5 & $1(20)$ & $5(100)$ & $5(100)$ & $0(0)$ & $3(60)$ & $0(0)$ & $1(80)$ & $4(80)$ & $4(80)$ & $2(40)$ \\
\hline
\end{tabular}

Key: $\mathrm{N}=$ Nitrofurantoin; $\mathrm{GN}=$ Gentamicin; $\mathrm{CPX}=$ Ciprofloxacin; $\mathrm{AM}=$ Ampicillin; $\mathrm{NA}=$ Nalidixic acid; $\mathrm{E}=$ Erythromycin; $\mathrm{CD}=\mathrm{Clindamycin}$; $\mathrm{CO}=$ Cotrimoxazole $; \mathrm{CF}=$ Cefuroxime; $\mathrm{CX}=$ Cephalexin

Table 2. Comparison of the Antibiogram of Gram positive and Gram negative test Organisms.

\begin{tabular}{|c|c|c|c|c|}
\hline \multirow{2}{*}{ Antibiotics } & \multicolumn{2}{|c|}{ No (\%) susceptible/sensitivity to: } & \multirow{2}{*}{$\mathbf{Z}$} & \multirow{2}{*}{ P-value } \\
\hline & Gram+ve $(n=22)$ & Gram -ve $(n=10)$ & & \\
\hline Nitrofurantoin & $9(40.9)$ & $2(20)$ & 1.22 & $\mathrm{P}>0.05$ \\
\hline Gentamicin & $13(59.1)$ & $9(90)$ & 1.83 & $\mathrm{P}>0.06$ \\
\hline Ciprofloxacin & $22(100)$ & $10(100)$ & 1.00 & $\mathrm{P}>0.99$ \\
\hline Ampicillin & $0(0)$ & $0(0)$ & 1.00 & $\mathrm{P}>0.99$ \\
\hline Nalidixic acid & $5(22.7)$ & $6(60)$ & $* 2.09$ & $\mathrm{P}<0.05$ \\
\hline Erythromycin & $3(13.6)$ & $0(0)$ & 1.86 & $\mathrm{P}>0.05$ \\
\hline Cotrimoxazole & $4(18.2)$ & $4(40)$ & 1.24 & $\mathrm{P}>0.05$ \\
\hline Cefuroxime & $14(63.6)$ & $5(50)$ & 0.53 & $\mathrm{P}>0.50$ \\
\hline Cephalexin & $11(50)$ & $5(50)$ & 0 & $\mathrm{P}>0.99$ \\
\hline
\end{tabular}

\section{Discussions}

The overall in-vitro sensitivity of the isolates revealed that all $100 \%$ test bacteria were sensitive to ciprofloxacin, followed by $90.6 \%$ to clindamycin, while all were resistant to ampicillin. This antibiotics sensitivity pattern favours the use of ciprofloxacin, clindamycin and gentamicin (which also showed up to $68.8 \%$ activity) in the treatment of UTI in children. This pattern of sensitivity has been noted by many authors in Nigeria [18, 19, 20, 21, 22, 23]. This very high sensitivity to ciprofloxacin was also reported by Ibadin et al., [24] in Benin City in a study involving 65 children with UTI. They isolated similar organisms as used in this study viz Staphylococcus aureus, Klebsiella pneumoniae and
Escherichia coli. In another study by the same authors also in Benin City involving children with acute Nephritic syndrome; the authors recorded $100 \%$ sensitivity of Staphylococcus aureus and Klebsiella pneumoniae to ofloxacin and ciprofloxacin which are Quinolones while E. coli was $75 \%$ sensitive to the antibiotics. Adeyemo et al., [19] and Brown et al., [22] in Ibadan also reported a very high sensitivity of the test organisms to ciprofloxacin. Akerele et al., [21, 23] have reported such sensitivity profile among bacteria isolated from pregnant women with ASB in Benin Cityand Imo State, Nigeria respectively, Anyadoh-Nwadike et al., [25] also reported high sensitivity of S. aureus from urine samples of pregnant women in Imo State, Nigeria to both ciprofloxacin (97.5\%) and Ofloxacin (94.2\%).

The use of Quinolones like ciprofloxacin and ofloxacin is 
however limited due to the fact that it can cause arthropathy in several species of immature animals. However, few and reversible joint symptoms have been reported in children with cystic fibrosis who were given ciprofloxacin. Therefore its benefits should be weighed against its potential risk especially when no alternative anti-infective agents is available or when other available drugs are less effective [22, 26, 27]. Brown et al., [22] in Ibadan, noted that the antibiotics sensitivity of isolates causing UTI in children with sickle cell disease were similar to that of the control group and that the bacterial isolate were resistant to gentamicin, amoxycilin, cotrimoxazole, and ampicilin. They therefore suggested that pefloxacin which is a Quinolone like ciprofloxacin should be considered in cases of multi-drug resistant organisms.

The very high sensitivity of the isolates to clindamycin in this study is worthy of note. This drug though with near complete absorption following oral administration is not commonly used in children most likely due to its side effects of diarrhoea and pseudo-membranous colitis. However, these side effects are more common in women and the elderly while low in children, thus the use of clindamycin can be considered in cases of multi-drugs resistance especially when Quinolones cannot be used [26, 27].

The overall sensitivity of all the test organisms in this study to gentamicin, a commonly used aminoglycoside was $68.8 \%$. E. coli and Pseudomonas aeuroginosa were $100 \%$ sensitive to it, Klebsiella spp. and Streptococcus faecalis were $66.7 \%$ sensitive respectively while Staphylococcus aureus was the least sensitive with $53.8 \%$ sensitivity to it. This is similar to $70.3 \%$ sensitivity recorded by Ibadin et al., [28] and 56.9\% reported by Akerele et al., [21, 23] in Benin City and Imo state, Nigeria respectively. In the study by Ibadin [28], E. coli was $62.5 \%$ sensitive to gentamicin while Klebsiella species was $50 \%$ sensitive to it. They recorded $100 \%$ sensitivity of Staphylococcus aureus to gentamicin as against $53.8 \%$ sensitivity in this study. However, it is similar to $48.3 \%$ sensitivity of $S$. aureus to gentamicin reported by Anyadoh-Nwadike et al., [25] from High Vaginal Swab (HVS) of pregnant women in Imo State, Nigeria. Other authors have also recorded moderate to high sensitivity of the organisms to gentamicin [20, 24]. Brown et al., [22] however reported that the organisms in their own study were resistant to gentamicin. The difference in the sensitivity pattern to gentamicin from different parts of Nigeria might be due to difference in prescription pattern and use of antibiotics known to cause selective repression of sensitive strains of bacteria and emergence of resistant ones [18].

Fifty nine point four percent of the organisms were sensitive to cefuroxime and $50 \%$ to cephalexin. This is similar to $74 \%$ sensitivity to cefuroxime recorded by Brown et al., [22] at Ibadan. Other authors have also recorded high to moderate sensitivity of UTI pathogens to ceftazidime another cephalosporin, while Ibadin [28], reported an emerging resistance to ceftazidime in his own study.

Poor invitro sensitivity to commonly used antibiotics like erythromycin, nalidixic acid, nitrofuraintoin, cotrimoxazole and complete resistance to ampicillin were noted in this study.
This has been the pattern in many other studies in Nigeria [18, $19,20,22,24]$. The reasons for this poor sensitivity has been blamed on the indiscriminate use of antibiotics occasioned by wide spread practice of self medication and availability of over the counter antibiotics. Use of sub-standard or fake drugs, drugs abuse and inappropriate dosages [8,9] of otherwise potent antibiotics are also possible reasons.

In contrast, Adeyemo [19] reported a good sensitivity to nalidixic acid and nitrofurantoin but this can be accounted for by the predominance of Klebsiella species (52.8\%) in his study which had good sensitivity to nalidixic acid and nitriofuraintoin. Klebsiella species accounted for only $9.4 \%$ of the organisms in this study. All of which were resistant to ampicillin, cotrimoxazole and erythromycin with $33.3 \%$ sensitivity to nalidixic acid and nitrofurantoin. However, Anyadoh-Nwadike et al., [25] also reported above $88 \%$ susceptibility of similar organisms isolated from pregnant women to nalidixic acid but below $60 \%$ susceptibility to nitrofurantoin.

All the test organisms in this study were resistant to ampicillin. This zero percentage was also recorded by Ibadin [28] in Benin City in children with Nephrotic syndrome. Similar experience was reported from Ibadan in both the patients with sickle cell disease and the control group [22]. Other authors have also recorded a very poor sensitivity of pathogenic bacteria organisms to ampicillin [19, 21, 24]. This may be due to development of resistance from use and misuse of commonly available over the counter antibiotics $[9,19,28$, 29].

Comparison of the antibiogram of Gram positive and Gram negative organisms revealed that there is no significant difference between the susceptibilities of both the Gram positive and Gram negative bacteria to nine of the used antimicrobial agents (Table 2). However, nalidixic acid showed significantly higher activity to Gram negative than Gram positive bacteria. This indicates that nalidixic acid should be more indicated in treatment of Gram negative bacterial infections.

Appropriate treatment of bacterial infections especially, UTI in the face of increasing drug resistance to commonly available first line drugs is challenging. However, Gupta [30] and Olanrewaju [31] proposed various preventive measures including exclusive breast feeding, proper hygiene, screening for ASB, early detection and prompt repairing of obstructive uropathies and stepwise anticipatory treatment of all confirmed cases in order to detect and prevent complication in pre-school children promptly. This is imperative because if these infections are not properly treated, they may become symptomatic leading to morbidity/mortality [12].

\section{Conclusions and Recommendations}

All the test bacteria were sensitive to ciprofloxacin, highly sensitive to clindamycin and cefuroxime while total resistance to ampicillin was revealed. Clindamycin and cefuroxime therefore should be used empirically while awaiting urine culture result since they are efficacious with very minimal side 
effects. Ampicillin should however be avoided.

Though ciprofloxacin has issues of side effects, in view of the $100 \%$ activity achieved by it, its use should be considered in children especially in the face of multidrug resistance. However, there is need for proper antibiogram surveillance of implicated pathogens prior to drug prescriptions in order to ensure holistic treatment of bacterial infections.

\section{References}

[1] M. Madigan and J. Martinko, Brock Biology of Microorganisms [11th Ed.]. Prentice hall. ISBN. 0131443291.

[2] M.L. Prescott, P.H. John, A.K. Donald, Textbook of Microbiology, 6th edition, 2005. McGraw Hill, New York.

[3] K. Todar, Online Textbook of Bacteriology. http://www.textbookofbacteriology.net/e.coli.html, 2009, Retrieved 30/06/2015.

[4] J. Jawetz, J.L. Melnick, E.A. Adelberg, et al., Medical Microbiology. 21st ed. Appleton and lange, connecticut, U.S.A, 1998.

[5] H.C. Davision, J.C. Low and M.E. J. Woolhouse, What is antibiotic resistance and how can we measure it? Trends Microbiol. 8: 554 -559, 2000.

[6] X.T. Cao, R. Kneen, T.A. Nguyen and D.L. Truong, "A comparative study of urinary tract infection, African Journal of Health Science, vol. 18 (3), PP 245 - 248, 1999.

[7] I.N. Okeke, A. Lamikanra and R. Edeman, "Socioeconomic and behavioural factors leading to acquired to acquired bacterial resistance to antibiotics in developing countries. Emerging Infectious Diseases, 1999, vol 5: 18 - 27.

[8] I.N. Okeke, O.A. Aboderin, D.K. Byarugaba, K.K. Ojo and J.A Opintan, "Growing problem of multi-drug resistant enteric pathogens in Africa. http://www.cdc.gov/EID/adherence and compliance to drug prescription and content/13/11/1640.htm. 2007Retrieved 10/09/2014.

[9] H.C. Neu, "The Crisis in Antibiotic Resistance. Science," 257: $1064-1072,1992$.

[10] S.O. Anyadoh, J. Akerele, U. Udum, "Prevalence of multidrug resistant Escherichia coli among pregnant Women in Owerri," International Journal of Medical Sciences and Technology, India, 2010, vol. 3 (3):17-20

[11] B. Blomberg, B.E. Olsen, S.G. Hinderaker, N. Langeland, P. Gasheka,"Antimicrobial resistance in urinary bacterial isolates from pregnancy women in rural Tanzania: Implications for public health," Scand J Infect Dis 2005; 37:262-268.

[12] S.L.M. Dairiki, "How serious is asymptomatic bacteriuria in children?" Contemp. Urol. 1998, vol. 10, PP 65 -69.

[13] L.E. Nicolle, S. Bradley, R. Colgan, J.C. Rice, A. Schaeffer, T.M. Hooton, "Infectious Diseases Society of America guidelines for the diagnosis and treatment of asymptomatic bacteriuria in adults. Clinical Infectious Diseases," 2005, 40(5):643-54.

[14] J. Akerele, and F. Okonofua, "Prevalence of asymptomatic genital infection among pregnant women in Benin-city, Nigeria," African Journal of Reproductive Health, 2002, vol. 6(3): 93-97.
[15] L.B. Travis and L.B. Brouhard, The genitourinary system. In: A.M. Rudolph, J.I.E. Hoffman and C.D. Rudolph eds. Rudolph Paediatrics. USA: Appleton and Lange. 1996, PP. 1388-92.

[16] J. C. Elo-Ilo, M.O. Iroezindu, I. Egbuonu, C.C. Ezechukwu and J.O. Chukwuka, "Prevalence of asymptomatic bacteriuria among pre-school children in Nnewi, South East Nigeria," Niger. J. Paed. Vol. 30, Issue 3; PP. 278 - 283, 8th Jan. 2013.

[17] M. Cheesbrough, Antimicrobial sensitivity tests In: Cheesbrough M ED. Medical laboratory manual for tropical countries vol. 11: Microbiology. London: Butterwort-Hienemann 1986 :196-205.

[18] Clinical and Laboratory Standards Institute (CLSI), Performance Standards for Antimicrobial susceptibility testing; 19th informational supplement M100-S19, 2009, CLSI, Wayne.

[19] M. O. Ibadin, "The prevalence of urinary tract infection in childhood nephritic syndrome," Nig J Paediatr 1997; 24:40-44.

[20] A.A. Adeyemo, R.A. Gbadegesin, T.N. Onyemenam, C.C. Ekweozor, "Urinary tract pathogens and microbial sensitivity pattern in childhood in Ibadan," Ann Trop paeditr. 1994: $14: 271-274$

[21] A.L. Rabasa, D. Shattima, "Urinary tract infection in severely malnourished children at the University of Maiduguri Teaching Hospital,” J Trop Pediatr 2002 ; 48:359-16.

[22] J. Akerele, F. Abhullimen, J. Okonofua, "Prevalence of asymptomatic bacteriuria among pregnant women in Benin City, Nigeria," J Obstet Gynaaecol 2001, vol. 21: 141-4.

[23] B. J. Brown, A.O. Asinobi, O.J. Fatunde, K. Osinusi, N. A. Fasina,"Antimicrobial sensitivity pattern of organisms causing urinary tract infection in children with sickle cell anaemia in Ibadan, Nigeria," West African Journal of Medicine, 2003.

[24] M.O. Ibadin, "Childhood urinary tract infections in Benin city, pathogens and antimicrobial sensititvity pattern," Jnl Med and Biomed Res 2002, vol. 1:22-8.

[25] Sylvia. O. Anyadoh-Nwadike , Sylvester. I. Okorondu, Ifeanyi .O.C. Obiajuru, Peter O. Nwadike, F.O. Nwaokorie and John .O. Akerele, "Comparative Study of the Prevalence and Antibiogram of Bacterial Isolates from the Urinary and Genital Tracts of Antenatal Patients," IOSR Journal of Pharmacy and Biological Sciences Volume 10, Issue 1 Ver. III (Jan -Feb. 2015), PP 15-19.

[26] A.P. Jr. William, Antimicrobial agents In: Hardman JG, Limbird LE, eds Goodman and Gilmans pharmacological basis of therapeutics, USA: McGraw-Hill , 2001, 1179-85.

[27] R. Doyle, K. Golberg, C.E. Harlods, J. Poeggd eds.,Handbook of Pediatric Drug therapy Pennsylvanian Spring house corporation, 2000, 167-9.

[28] M.O. Ibadin, P.O. Abiodun, Urinary tract infection in children with Acute Nephritic syndrome. Ann. Biomed Sci. 2000, vol. $1: 23-9$.

[29] A. Onanuga, A.R. Oyi, J.A. Onaolapo,"Prevalence and susceptibility pattern of methicillin resistant Staphylococcus aureus isolates among healthy women in Zaria, Nigeria," African Journal of Biotechnology, 2005, 4: 1321-1324.

[30] N.R. Gupta, T. Mattoo, "Urinary tract infection in children, synopsis: A current survey of world literature in Paediatrics," 2002, vol 4 
[31] T.A. Olarenwaju, "Prevention of urinary tract infection in children in the tropics," Post Grad Doct Afr. 2002, vol. 24: 29-31. 